\title{
Comparison of SiC-Based DC-DC Modular Converters for EV Fast DC Chargers
}

\author{
Mohammed Alharbi ${ }^{1}$, Mohamed Dahidah ${ }^{1}$, Volker Pickert ${ }^{1}$ and ${ }^{2}$ James Yu \\ ${ }^{1}$ School of Engineering, Newcastle University, Newcastle upon Tyne, United Kingdom \\ ${ }^{2}$ Scottish Power Energy Networks, Blantyre, United Kingdom
}

\begin{abstract}
This paper introduces a level 3 charging system which aims to reduce the charging time to less than 15 minutes with $350 \mathrm{~kW}$ charging power. Two architectures of a fast charging station based on the isolation requirement through low and high-frequency transformers are introduced and discussed. Focusing on the DC-DC charging stage, this paper also provides a detailed comparison of the Dual Active Bridge (DAB) converter and the Interleaved Buck Converter (IBC), which are considered as two of the most suitable converters that can serve as a fast DC charger. Technical evaluation and comparison based on different performance indices such as volume, efficiency, number of components etc. as well as simulation of the two converters are presented. Finally, comparison results are introduced and a final discussion and conclusion are presented on which topology seems more optimum to be used as a fast DC charger.
\end{abstract}

Keywords -Fast DC charger; Electric vehicles (EVs); DC-DC power converters; DAB converter; Multiphase IBC Converter

\section{INTRODUCTION}

Nowadays, Electric vehicles (EVs) are gaining significant attention as an environmental-sustainable and cost-effective solution when compared to fossil-fuel conventional cars. However, one of the main challenges to their large-scale implementation is the long charging time. Despite the enormous benefits of EVs, long charging time and lack of charging facilities are two of the major barriers that are preventing the large-scale penetration and spared of EVs. Consumers are still more inclined to use conventional cars as it takes 2 to 5 minutes to refuel an internal combustion engine vehicle (ICEV) while the charging process of an EV battery takes around 4 to 20 hours using current residential (Level 1) and some public (Level 2) charging options [1]. Hence, the widespread and adaption of EVs will be directly related to the development and availability of fast chargers which should recharge EVs in reduced times (e.g. $<15$ minutes). In particular, fast chargers or else, known as (Level 3 or off-board charger), are installed outside the vehicle and hence the name "off-board", mainly in public places [1]. For the purpose of reducing the charging time, the power rating of Level 3 chargers is usually classified as any charging power higher than $36 \mathrm{~kW}$ as detailed in Table 1 [1], [2]. CHAdeMO and CCS Combo, which are the two most common worldwide standards of Level 3 charging, announced the development of $350-400 \mathrm{~kW}$ charging protocol by 2020 [3], [4].

Furthermore, the architecture of a fast charging station can be either recognised by using an $\mathrm{AC}$ bus, where each charging unit has its independent ac-dc stages; or alternatively using a single ac-dc stage with a higher power rating to offer a common DC bus for various loads (i.e. EVs). The latter is a more feasible solution as the EV batteries are inherently DC, resulting in minimising the cost, size and increasing the efficiency of the overall system. In addition, this configuration simplifies the integration of renewable energy sources (RESs) and battery energy storage systems (BESs) into the charging station [5], [6].

One of the main requirements of a fast charging station, defined by the Society of Automotive Engineers (SAE) standard, is the galvanic isolation between the distribution grid and the battery pack [7]. This can be achieved by two different architectures: either 1) through using a low-frequency (LF) transformer at the input side or 2) through the implementation of high-frequency (HF) transformer included in the DC stage by means of isolated DC-DC converters [8].

A central converter (AC-DC) stage performs the grid connection and the DC bus voltage regulation tasks. Once performed, each fast-charging unit must then be equipped with high power DC-DC converters. These converters play a vital role in achieving a satisfactory efficiency of the system and minimising the charging time. Therefore, highly efficient converters should be selected in order to reduce the loss in the process of power transfer to the battery pack and additionally reducing the charging voltage and current ripples to prevent possible damage to the battery [2], [9]. The output voltage of the converters is regulated depending on the type of the EV battery to charge the battery pack.

Depending on the selected architecture to meet the isolation requirement, many isolated and non-isolated converters have been implemented as a fast DC charger unit [10], [11]. Two of the most suitable isolated and non-isolated converters for such a high-power application are the dual-active bridge (DAB) and the interleaved buck converter (IBC) converters, respectively [8]. These two particular converters, when compared to other available power electronics topologies, can attenuate the severe electrical constraints such as the required high output current and the high DC bus voltage at the input and output sides, respectively, as well as enabling bidirectional flow allowing for vehicle-to-grid (V2G) service [8].

The aim of this paper is to through study these two converters and compare them in terms of different performance indices such as volume, efficiency, number of components etc. as well as analysing the advantages and drawbacks of the two topologies. 
Table 1 Charging Power Levels [1]

\begin{tabular}{ccc}
\hline $\begin{array}{c}\text { Power Level } \\
\text { Types }\end{array}$ & $\begin{array}{c}\text { Expected } \\
\text { Power Level }\end{array}$ & $\begin{array}{c}\text { Charging } \\
\text { time }\end{array}$ \\
\hline $\begin{array}{c}\text { Level 1 } \\
\text { (on-board) }\end{array}$ & $1.4 \mathrm{~kW}(12 \mathrm{~A})$ & $7-17$ \\
120 Vac (US) 230Vac (EU) & $1.9 \mathrm{~kW}(20 \mathrm{~A})$ & hours \\
$\begin{array}{c}\text { Level 2 } \\
\text { (on-board) }\end{array}$ & $4 \mathrm{~kW}(17 \mathrm{~A})$ & $0.4-7$ \\
hours \\
230 Vac (US) 400 Vac (EU) & $19.2 \mathrm{~kW}(80 \mathrm{~A})$ & \\
$\begin{array}{c}\text { Level 3 } \\
\text { (off-board) }\end{array}$ & $50-350 \mathrm{~kW}$ & $0.1-0.5$ \\
$\mathbf{2 0 8 - 6 0 0 ~ V a c}$ & $\left(\mathrm{I}_{\max }=400 \mathrm{~A}\right)$ & hours \\
$\mathbf{2 0 0 - 1 0 0 0 ~ V d c}$ & & \\
\hline
\end{tabular}

\section{Converter Performance}

\section{A. Performance Indices:}

Various quantities need to be considered for the design of power electronics converters, which are termed as 'performance indices' as shown in Fig.1. Their continuous improvement is one of the main design objectives for future (off-board) EV chargers. A summary of the performance indices is presented below:

\section{1) Power Losses (Efficiency):}

The efficiency considered as the main comparison quantity and gaining more importance to other quantities. The efficiency of a converter is expressed as:

$$
\eta=100 \cdot \frac{P_{o}}{P_{i}}[\%]
$$

where $P_{o}$ is the output power and $P_{i}$ is the input power. Efficiency is directly affected by power losses which in turn affected by three main sources: semiconductors devices, passive components, and auxiliary components. Losses result by the semiconductor devices can be divided into two parts, switching, and the conduction losses. The switching losses are directly related to switching frequency, i.e. increasing the switching frequency results in increasing the switching losses. However, designers tend to use high frequency to reduce the size of the passive components [12],[13]. Hence, soft-switching techniques are normally employed aiming to reduce the switching losses with high switching frequency operation. The passive components, such as inductors and capacitors, results in almost $20 \%$ of the total losses [14]. Hence, the less the number of passive components the less is the losses. Auxiliary losses defined as the total losses of the power supply of the cooling system, the digital control, and the power semiconductor drivers. A lower weight, volume and cost are achieved by reducing the cooling requirements and the number of semiconductor devices [13], [15].

\section{2) Volume (Power Destiny) and Weight (Specific Power):}

Power density represents how compact a converter is, whereas the specific power represents the nominal power of a converter in terms of weight. Multiple advantages result from a low converter volume and weight such as simple handling, installation and maintenance of the converter [15]. Lower weight and consequently lower cost converter can be achieved by increasing the switching frequency which results in reducing the size of passive components [13].

\section{3) Failer Rate (Reliability):}

Reliability is defined as the ability of a system or component to perform its required functions under a stated condition for a specific period of time. The reliability of a system is increased by increasing the number of components. However, this results in higher weight and cost of the system. Hence, a trade-off analysis is required [13].

\section{4) System Cost (Relative Cost):}

The system cost of a high-power converter is typically high due to the use of efficient and high power rated devices. The lower the number of components the lower is the system cost. A qualitative measure to determine the overall system cost can be expressed by the 'relative cost' as follows [13]:

$$
\sigma=\frac{P_{o, n o m}}{C}[\mathrm{~kW} / \$, \mathrm{~kW} / €]
$$

where $P_{o, n o m}$ is the nominal power and $C$ is the total cost of a system.

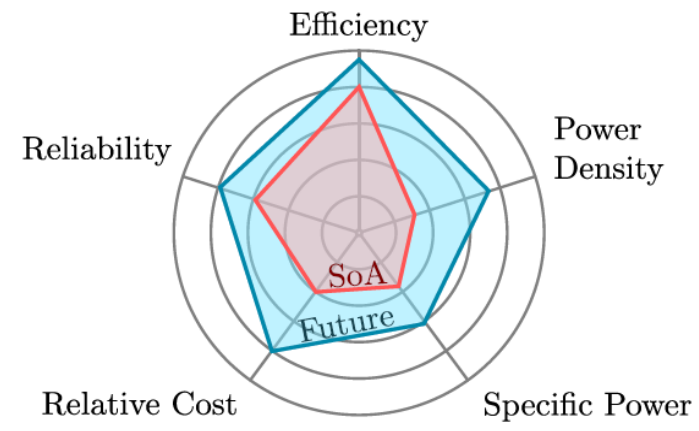

Figure 1 current and future expected performance indices of a power electronic converter system [13]

\section{B. Wide Band-Gap Devices:}

Wide band-gap semiconductors present superior material with well improved physical limits when compared to current Silicon (Si) technology such as high-voltage capability, low onstate resistance, high switching speed and temperature operation. Currently, the two-promising wide band-gap semiconductor devices are the Silicon Carbide $(\mathrm{SiC})$ and Gallium Nitride (Gan) [16]. The implementation of these new power semiconductor devices will introduce an improvement in the operation of existing power converters and surely new power converters resulting in an increase in the efficiency of the converter. Operating converters in hard-switching with a few hundred kilohertz using Si devises is only possible by employing soft-switching techniques whereas it is feasible with using wide band-gap devices. Higher efficiency is achieved with wide band-gap devices due to the low voltage drop across the devices, as a result of the small on-resistance of the device, resulting in low conduction losses. Switching losses are also minimised due to the short switching time of the device [16], [17]. 


\section{Charger Structure AND TOPOLOGIES}

Due to the high power demand absorbed from the grid and in order to cope with the challenge of fast charging multiple EVs simultaneously, one solution is to connect the charging station system to a medium voltage (MV) grid connection [5], [18].

The classical approach for the conversion form AC-DC (or DC-AC e.g. bidirectional power flow) is to employ an LF transformer and a rectifier/inverter as the first conversion stage, as shown in Fig. 2a. As the input voltage of the charging system is in several $\mathrm{kVs}$, the $\mathrm{AC} / \mathrm{DC}$ stage should withstand the high input voltage with low power losses. Multilevel converters would be the best candidate to interface with the grid due to their capabilities of withstanding high input voltage [19], [20]. This AC-DC conversion stage guarantees power factor correction and produces a constant high output DC bus voltage for the second conversion stage. The second conversion stage in this configuration can be a non-isolated converter type. The alternative architecture of a fast DC charging station is shown in Fig. 2b. An isolated converter is employed as the second conversion stage to perform the isolation requirements through an integrated HF transformer whereas the first AC-DC stage remains the same as the first architecture. However, a higher rated $\mathrm{AC} / \mathrm{DC}$ converter is required to withstand the high input voltage [2], [21]. The first conversion stage (AC-DC) is out of the scope of this paper and will not be discussed any further.

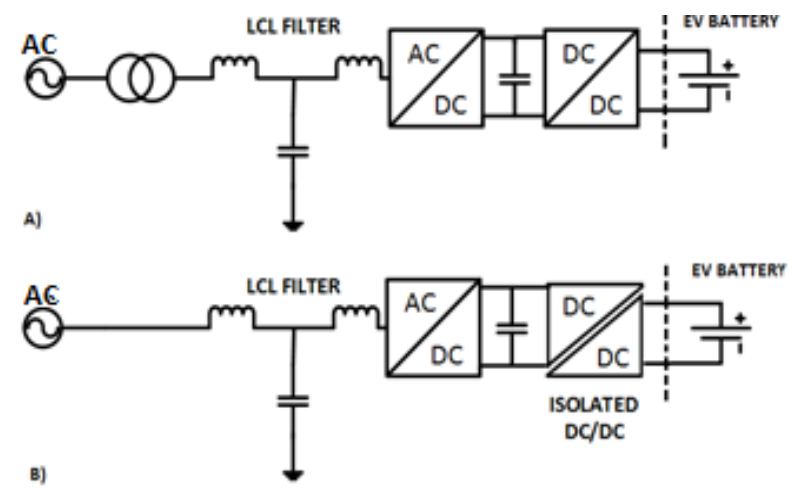

Figure 2 Level 3 fast charging: a) LF transformer; b) HF transformer [2]

\section{The FAST DC CHARger SPECIFICATIONS}

In addition to the general aforementioned comparison quantities, some other important requirements and factors must be considered when designing a fast DC charger. The first essential requirement of a charger is the ability to provide a wide dc output voltage to interface different types of EVs occupied with different battery technologies as well as the ability to regulate the output voltage according to the voltage of the EV battery pack. The voltage range of future $350 \mathrm{~kW}$ fast DC chargers is 200-920 V [3], [22]. The second requirement is the electrical quantities (voltage and current) ripples as the output of the converter which is set to a very narrow value to guarantee secure operation of the converter and prevent any damage to the connected battery pack [23]. In fact, the maximum current and voltage ripples are set at $5 \%$ and $1 \%$ of the nominal value, respectively [2], [11], [24]. Another requirement is the ability to deliver high power to reduce the charging time to less than 15 minutes. These requirements would require a higher number of semiconductor devices to share the high current and voltage.

The DAB and IBC topologies were found the most suitable converters that are capable of meeting the above requirements [8], [11]. These two converters are compared, and the best topology is chosen based on several aspects: efficiency, converter volume, the number of components, current ripple, and control complexity. A resistive load has been considered, as the main purpose of the paper is to compare the performance of the two converters in terms of operation, efficiency, etc. Hence, the model of the battery is not required at this stage.

The switching frequency will determine the size of the passive elements and losses in the semiconductor devices, while the right components can help in reducing the losses. A switching frequency $f_{s w}$ of $50 \mathrm{kHz}$ is considered for the two converters in this paper, which is reasonable when high power $\mathrm{SiC}$ devices are utilised. A commercially available B6C (CAS300M17BM2) SiC module is considered to be used for both converters in this study [25].

The specifications of the fast DC charger module are summarised in Table 2. The dc charger module compromises of parallel DC-DC converters to meet the desired power level of $350 \mathrm{~kW}$. Hence, 5 parallel cells are required, each rated at 70 $\mathrm{kW}$. Connecting the converter output in parallel enables high charging current and hence faster charging. The maximum output current of each cell is $350 \mathrm{~A}$. This output current is under minimum output voltage i.e. $200 \mathrm{~V}$. For voltage levels higher than $200 \mathrm{~V}$, the maximum output current is reduced to keep the output power around $70 \mathrm{~kW}$ for each cell. For instance, maximum output current in the maximum output voltage, 920 $\mathrm{V}$, is limited to $76 \mathrm{~A}$. The main reason for this current reduction is to fulfil the maximum operating condition of the line connected devices like cables, switches and power electronic devices. In this work, the output nominal voltage is chosen to be $500 \mathrm{~V}$.

Table 2 Specifications of the fast DC charger

\begin{tabular}{|c|c|}
\hline Parameters & Charger unit \\
\hline Internal DC-link Voltage & $1200 \mathrm{~V}$ \\
\hline Effective Rated Power $P_{\text {ch,eff }}$ & $\begin{array}{c}350 \mathrm{~kW} / 5 \text { parallel converters } \\
\text { of } 70 \mathrm{~kW}\end{array}$ \\
\hline Battery Pack Voltage $V_{\text {bat }}$ & $\begin{array}{c}200-920 \mathrm{~V} \\
\text { nominal }=500 \mathrm{~V}\end{array}$ \\
\hline $\begin{array}{c}\text { Charging Current } \mathbf{I}_{\mathrm{ch}} \\
\text { (Each cell) }\end{array}$ & $\begin{array}{c} \pm 140 \mathrm{~A} \\
\operatorname{Max}=350 \mathrm{~A}\end{array}$ \\
\hline Switching frequency $\left(F_{s}\right)$ & $50 \mathrm{kHz}$ \\
\hline $\begin{array}{c}\text { Battery Voltage Ripple } \\
\text { (peak-peak) }\end{array}$ & $<1 \%$ \\
\hline $\begin{array}{l}\text { Inductor current ripple } \\
\text { (peak-peak) }\end{array}$ & $<5 \%$ \\
\hline
\end{tabular}

V. Design Of The DC-DC Converters Based On The DaB AND IBC TOPOLOGIES

\section{A. Design of DAB Converter:}


The Dual Active Bridge (DAB) is one of the most promising DC-DC circuit topologies for high power applications [26]. The series and/or parallel connections of multiple DABs enable to increase the current and power making this topology feasible for high power charging applications (e.g. fast DC chargers). One of the main advantages of the DAB converter is the galvanic isolation which is provided within the converter by means of an HF transformer. Hence, no bulky line frequency transformer is needed in the front-end of the charging system.

Fig. 3 shows the schematic diagram of the bidirectional DAB converter with SiC MOSFET as switching devices. The converter consists of two active full bridges linked with an inductive element where the first side operates as an inverter and the second side operates as a rectifier. The energy transfer leakage inductor $L_{I}$ is used as the main energy storage and transfer element between the two bridges [27], [28]. For a battery charging application, a DAB converter can operate as a buck converter to transform the bus voltage to charge the battery and on the contrary, operate as a boost converter transforming the battery voltage to the bus voltage when discharging [29]. The amount of power being transferred $P_{D}$ and the direction of the current is determined by the phase shift $d$ between the primary $\mathrm{V}_{1}$ and secondary $\mathrm{V}_{2}$ voltages. In addition, other parameters that are affecting the power transfer are the transformer turn ratio $N$, the leakage inductor $L_{l}$ and the $f$ switching frequency [27].

$$
P_{D}=\frac{N \cdot V_{1} \cdot V_{2}}{2 L f} d(1-d)[\mathrm{W}]
$$

where $L$ is the sum of the transformer leakage inductance $L_{1}$ and the auxiliary inductances of the transformer.

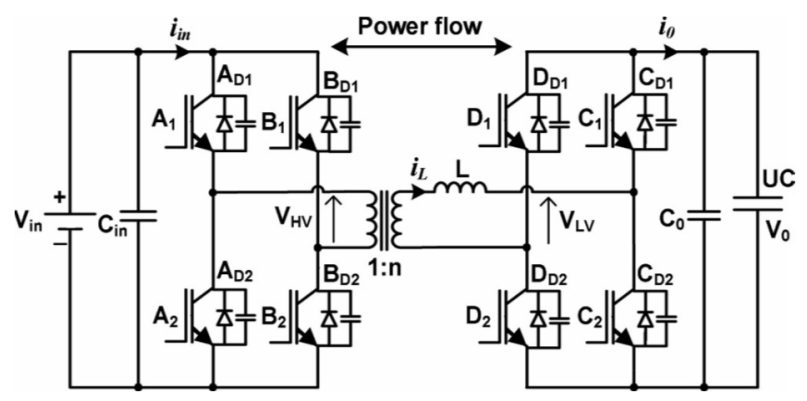

Figure 3 Topology of DAB converter [30]

From the previous equation, it can be derived that the maximum amount of transferring power occurs when $d=0.5$. However, operating the converter at the maximum phase-shift e.g. $d=0.5\left(90^{\circ}\right)$ results in high reactive currents flowing through the converter and consequently reducing the efficiency of the converter due to power losses of power devices [30].

$$
P_{D \max }=\frac{N \cdot V_{1} \cdot V_{2}}{8 L_{\max } f}[\mathrm{~W}]
$$

An output capacitor $\mathrm{C}_{\text {out }}$ is employed to smooth out the output voltage, which can be calculated as follows:

$$
C_{\text {out }}=\frac{50 \cdot P_{o}}{\left(V_{o}\right)^{2} \cdot f}[\mathrm{~F}]
$$

Three main modulation techniques can be applied to DAB converters, namely, single-phase-shift (SPS), extended-phaseshift (EPS) and dual-phase-shift (DPS) control. However, the most commonly used control technique for DAB is the SPS control due to its advantages of simple control, high dynamic and small inertia [27]. Each bridge of the DAB converter is driven by a $50 \%$ duty cycle square voltage waveform. The resulted output $V_{l}$ and $V_{2}$, which are the equivalent ac output voltages of full-bridges $H_{1}$ and $H_{2}$, respectively, and the inductor current $i_{L}$ of the DAB converter are shown in Fig. 4.

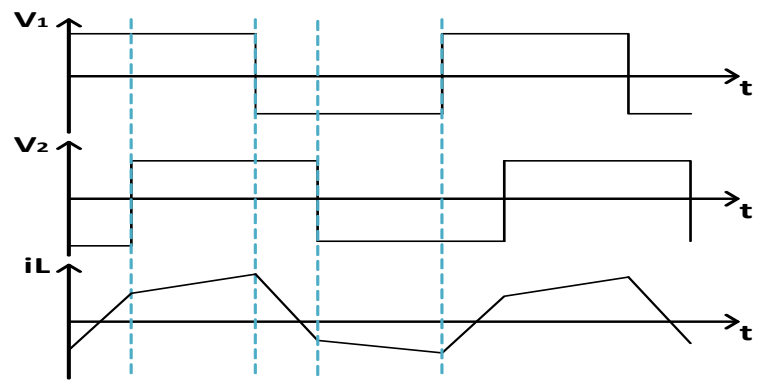

Figure 4 Typical voltage and current waveforms of the DAB converter

The maximum allowable leakage inductance value of the DAB converter can be calculated from (4), which is set as at $80 \%$ of $L_{\max }$ to ensure sufficient bandwidth of the duty cycle [28]. Considering a switching frequency of $50 \mathrm{kHz}$, this yields the final design value of $L_{1}=41.14 \mu \mathrm{H}$. At this value of leakage inductor, the phase shift is calculated from (3) to be as $d=0.28$.

The HF transformer is the main component in the design of an isolated converter. A transformer with Amorphous material was selected due to its high saturation flux density $B_{\text {sat }}$ presenting the best balance between cost losses per unit volume, operating temperature, and availability when compared with other magnetic materials such as ferrite and Nanocrystalline [31]. All the data needed to design the HF transformer and the calculated parameters of the transformer are summarised in Table 3.

Table 3 HF Transformer parameters

\begin{tabular}{c|c}
\hline $\begin{array}{c}\text { Magnetic core } \\
\text { Saturation flux density } \\
\left(\mathbf{B}_{\max }\right)\end{array}$ & Amorphous \\
Primary winding $\left(\mathbf{N}_{\mathbf{1}}\right)$ & $1.56[\mathrm{~T}]$ \\
Secondary winding $\left(\mathbf{N}_{\mathbf{2}}\right)$ & 16Turns, 150 strands, AWG 23 \\
Current density $(\mathbf{J})$ & $4.5\left[\mathrm{~A} / \mathrm{mm}^{2}\right]$ \\
Primary resistance & $7.93[\mathrm{~m} \Omega]$ \\
Secondary resistance & $1.4[\mathrm{~m} \Omega]$ \\
\hline
\end{tabular}


The DAB converter and the parameters of the HF transformer were simulated and calculated off-line using MATLAB. The gate signals of the two bridges operating at $50 \%$ duty ratio, implemented with SPS modulation are shown in Fig. 5, while the AC voltage and current waveforms are shown in Fig. 6. The secondary voltage is shifted by $d=0.28\left(49.7^{\circ}\right)$ from the primary voltage in order to avoid any resulted excessive reactive power when operating the converter at the maximum phase shift of $d=0.5\left(90^{\circ}\right)$ as mentioned earlier. The primary and secondary RMS currents at the high-voltage and low-voltage sides are $I_{1}=72.8 \mathrm{~A}$ and $I_{2}$ $=174.7 \mathrm{~A}$, respectively. The output voltage and output current of the converters are shown in Fig. 7 and Fig. 8, respectively. The output voltage at the full load is at around $498 \mathrm{~V}$ with a peak to peak ripple voltage of $2.8 \mathrm{mV}$. The transformer losses are calculated according to [32] and are summarised in Table 4.

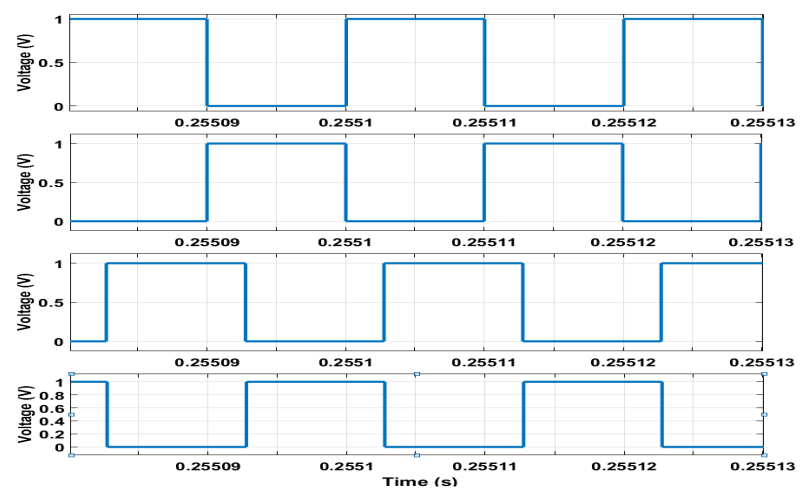

Figure 5 Gate signals of the DAB converter

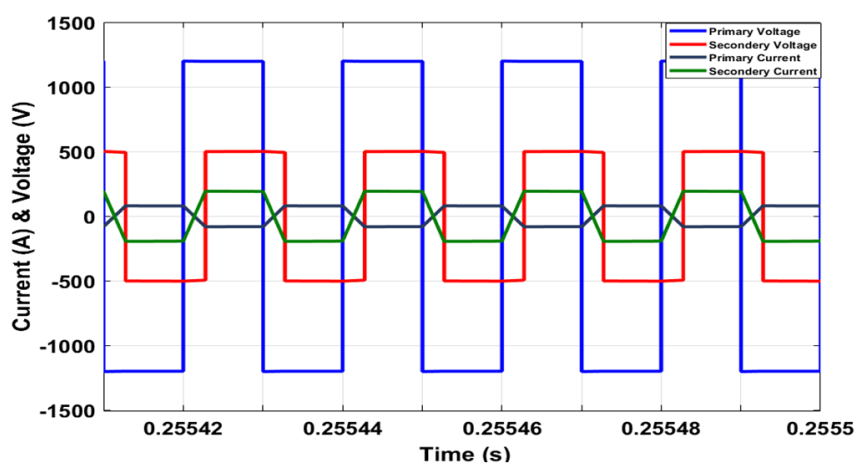

Figure 6 Operational waveforms of DAB converter

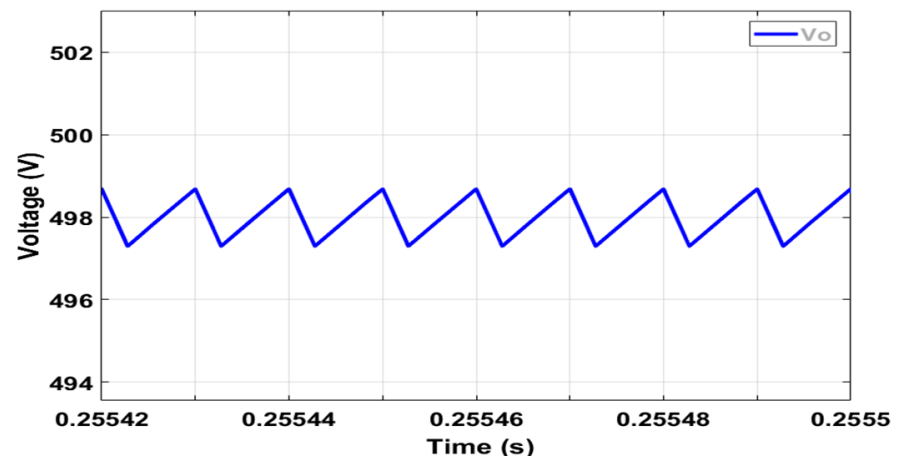

Figure 7 Output voltage of DAB converter

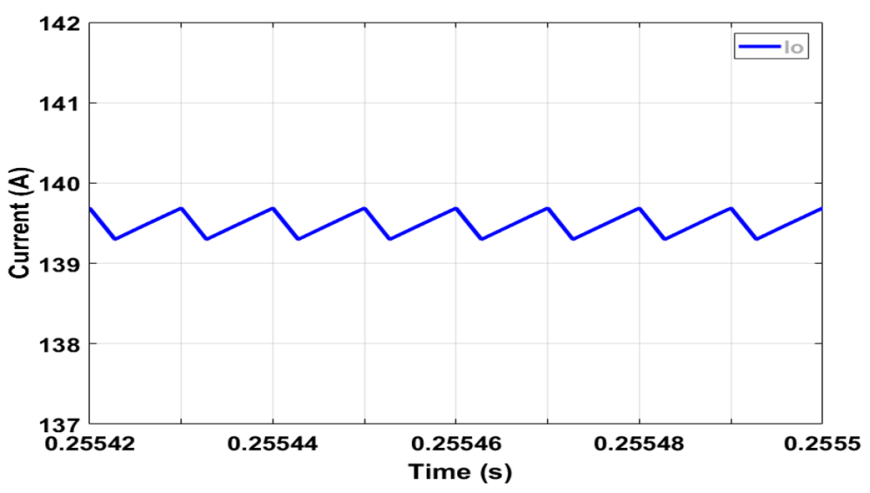

Figure 8 Output current of DAB converter

Table 4 HF Transformer losses

\begin{tabular}{c|c}
\hline Parameter & \multicolumn{1}{c}{ Value } \\
\hline Core losses $\left(\mathbf{p}_{\mathrm{fe}}\right)$ & $84.36 \mathrm{~W}$ \\
Copper losses $\left(\mathbf{p}_{\mathrm{cu}}\right)$ & $1.54 \mathrm{~kW}$ \\
Total losses $\left(\mathbf{p}_{\text {total }}\right)$ & $1.63 \mathrm{~kW}$ \\
Transformer efficiency $\left(\boldsymbol{\eta}_{\mathbf{t}}\right)$ & $97.73 \%$ \\
\hline
\end{tabular}

\section{B. Design of IBC Converter:}

A different approach to an off-board charger at the input stage of the system is through using an LF transformer wherein such case, non-isolated converters can be employed as a DC charger. Typically, at low power application, the buck converter can be used to step down the input voltage, which is however not feasible for high power applications. Instead of using an over-sized single-phase converter, multiphase interleaved buck converters (IBC) can be employed for high current applications due to its advantage of sharing the output current between the number of phases $N$ resulting in lower rated inductors and power switching devices. Moreover, the efficiency of the converter is typically high due to the fact that fundamental frequency is multiplied by $N$ resulting in a higher system frequency, improved transient response, smooth output current with low ripple and low EMI and output filters size [33], [34]. However, as the number of phase's increases, the number of active switches, cost, weight, complexity, and size also increases.

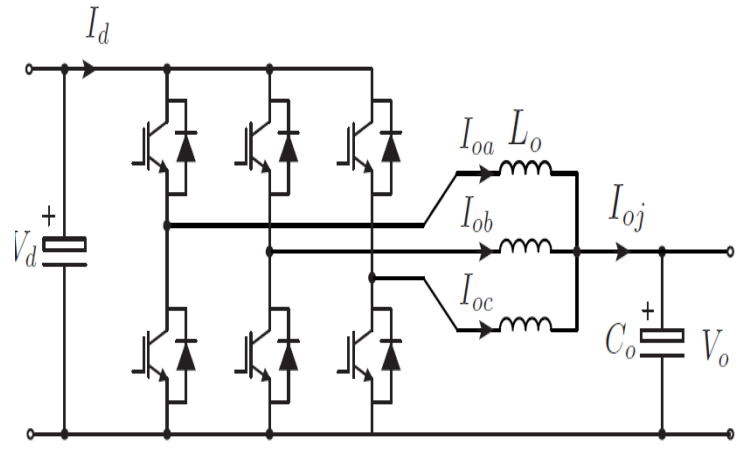

Figure 9 Topology of three-phase IBC [6] 
Hereafter, a three-phase buck converter is considered in this paper as shown in Fig. 9. The upper and lower active switches of each phase operate in a complementary manner and each phase is shifted by $360^{\circ} / \mathrm{N}$ from one another. In this case, the switches have a phase shift of $120^{\circ}$ between them with $50 \mathrm{kHz}$ switching frequency.

The passive components of the three-phase IBC converter are designed and calculated according to the specifications of the fast charger shown in Table II. The converter is assumed to be operating under continuous conduction mode (CCM) as the operation in discontinuous conduction mode (DCM) yields to vital limitations in high current applications especially on active components as well as high core losses in inductors [35]. The output inductor value per phase can be obtained from (6) as follows:

$$
L=\frac{V_{o} \cdot(1-D)}{f . \Delta i_{L}}[\mathrm{H}]
$$

where $f$ is the switching frequency, $D$ is the duty cycle of the converter and $\Delta i_{L}$ is the current ripple of each phase. Considering the advantage of current cancelation in the IBC , which results in a low output current, a current ripple of $\Delta i_{L}=$ $25 A$ was selected for each phase to minimise the size of the inductor [36]-[38]. This leads to an inductance value of $L_{1}=$ $233.33 \mu H$ per phase.

The output capacitor at the charger output furthermore smoothes the output charging current and satisfy the required voltage ripple of $>1 \%$. The minimum output capacitor is calculated using (7), where $\Delta i_{L}$ is the ripple current of a single phase of the converter.

$$
C_{\min }=\frac{\Delta i_{L}}{8 \cdot f \cdot\left(\Delta V_{\text {out }} \cdot V_{\text {out }}\right)}[\mathrm{F}]
$$

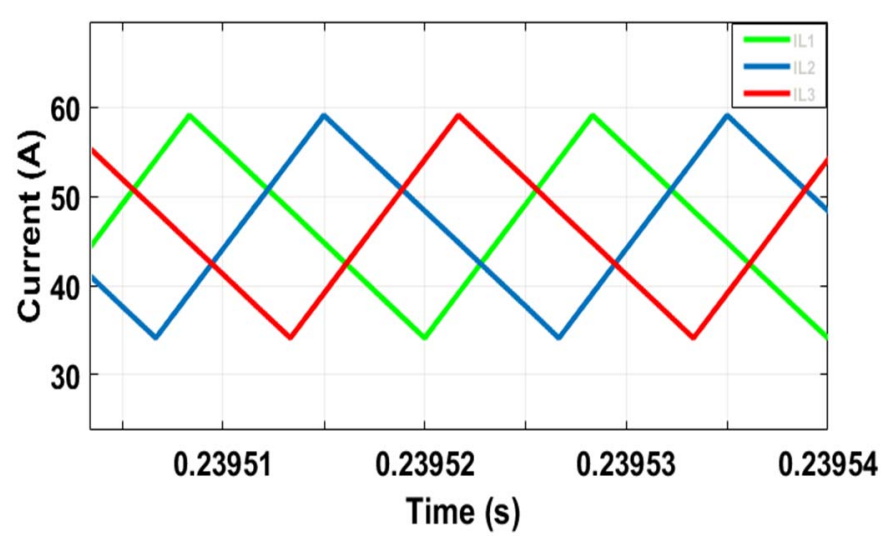

Figure 103 -phase inductor currents of IBC

The inductor currents of each phase of the converter, shifted by $120^{\circ}$ from each other as shown in Fig. 10. It can be seen that the current is equally shared between each phase with an average value of $46.6 \mathrm{~A}$, which corresponds to the total output current of 140 A divided by $N$ (i.e. $N=3$ in this paper), and a peak-to-peak ripple value of $25 \mathrm{~A}$.

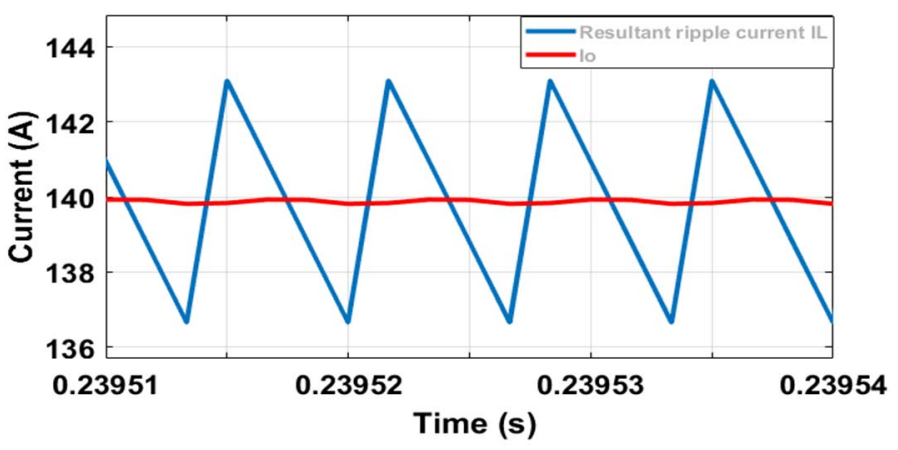

Figure 11 Output current of IBC

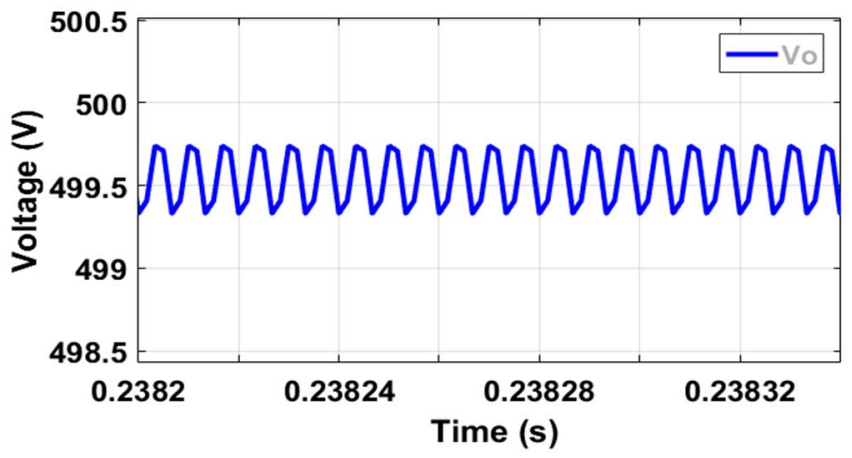

Figure 12 Output voltage of IBC

The total output current due to the cancellation effect of summing up all the three-individual phase inductor current is shown in Fig. 11 resulted in reducing the output inductor ripple to $6.4 \mathrm{~A}$. This ripple is further reduced to $0.1145 \mathrm{~A}$ by the output capacitor at the load side. Fig. 12 shows that the output voltage at full load, which is around $500 \mathrm{~V}$ with a peak to peak ripple voltage of $1 \mathrm{mV}$, which is way less than the value specified of $10 \mathrm{mV}$ due to the interleaving technique.

\section{COMPARISON AND DISCUSSION}

The DAB and IBC converters are compared considering the performance indices aforementioned utilising the same rated semiconductor devices and switching frequency of $50 \mathrm{kHz}$ providing the same output power of $70 \mathrm{~kW}$. Table 5 shows a quantitative comparison between the two converters, in which some features of each converter are presented.

Table 5 Comparison of DAB and IBC converters

\begin{tabular}{c|cc}
\hline Criteria & $\begin{array}{c}\text { Dual active } \\
\text { bridge } \\
\text { (DAB) }\end{array}$ & $\begin{array}{c}\text { Interleaved } \\
\text { buck converter } \\
\text { (IBC) }\end{array}$ \\
\hline $\begin{array}{c}\text { Output capacitor } \\
\text { Inductor }\end{array}$ & $41.14 \mu \mathrm{HF}$ & $16 \mu \mathrm{F}$ \\
Transformer & $\checkmark$ & $233.33 \mu \mathrm{H}$ \\
Active switches & 8 & $\times$ \\
Internal isolation & $\checkmark$ & $\times$ \\
Bidirectional power \\
flow
\end{tabular}


The IBC required merely a $16 \mu \mathrm{F}$ output capacitor in order to regulate the output voltage and filter out the ripple. This is due to the current ripple cancellation, resulted from the interleaving technique, as well as the output inductors since they are directly connected to the load. On the other hand, a bulky capacitor of $280 \mathrm{mF}$ is required in the DAB converter. Ideally, to ensure the battery is efficiently charged and its lifetime is not affected, the output current ripple and the output voltage ripple of the converters should be minimum. These two factors can be easily achieved and were significantly lower in the simulation results of the IBC converter.

Due to the current sharing technique in the three-phase IBC, three output filter inductors of $233.33 \mu \mathrm{H}$ minimally rated at $47 \mathrm{~A}$ are required, while the leakage inductor of the DAB converter is $41.14 \mu \mathrm{H}$ and rated at a minimum full output current of $140 \mathrm{~A}$. The magnetic elements such as the transformer and inductors have the most effect on the volume and weight of a converter. Hence, even though, IBC converter requires 3 inductors, the overall volume and size of the transformer considerably outweigh the volume and weight of the DAB converter.

Moreover, with the aforementioned advantages of $\mathrm{SiC}$ devices, IBC converters can relatively operate at very high switching frequency (e.g. $>300 \mathrm{kHz}$ ) resulting in further reduction the output filter components (equation (6)), whereas the nominal frequency of the HF transformer within the DAB converter is usually limited to $<120 \mathrm{kHz}$, especially for high power converters, due to the electromagnetic compatibility (EMC) and harmonic emissions [39].

In terms of the number of active switches, the DAB converter has more switches than the three-phase IBC converter. The active switches of the DAB converters must be rated and withstand the highest current in the converter in case of bidirectional power flow, whereas the switches in the IBC converters is usually minimally rated at $I_{o} / N$, where $\mathrm{N}$ is the number of phases. As some immediate consequences, the cost and the conduction losses are significantly lower in IBC when compared to $\mathrm{DAB}$ due to the current sharing between the phases.

Moreover, in addition to the conduction and the switching losses, DAB converter suffers from the HF transformer losses in high current applications resulting in reducing the overall efficiency of the converter. Contrarily, the efficiency of the IBC is only affected by the conduction and the switching losses where in which is the conduction losses is lower due to the current sharing feature as highlighted earlier.

The DAB converter as mentioned provides the advantage of galvanic isolation by means of HF transform in the DC-DC converter stage, which results in eliminating the need for a bulky LF transform in the front end of the charging system. However, deviation from the nominal conditions (e.g. output voltage) in which the HF transformer was initially designed for, would result in reducing the system efficiency. Hence, for wide input/output voltage variation applications, the use of DAB converter is limited due to this disadvantage [40], [41].
Moreover, the semiconductor devices of the AC/DC converter stage must be highly rated due to the connection of the MV grid without the use of up-front LF transformer.

Hence, since an LF transformer seems necessary in the front-end of a high-power charging system, a non-isolated converter such as the discussed IBC is preferable to serve as a dc charger due to its compactness, reliability, efficiency and relatively simple control when compared to other candidates of high-power topologies.

In addition, for a modular configuration of the dc chargers in order to obtain high charging output current and consequently reduce the charging time, the rated power of a single cell DAB converter is limited due to the power stress on the semiconductor devices and the conduction losses. On the other hand, a higher power can be achieved with less number and a lower power rated components by means of a single cell of an IBC with multiple phases as the output current is separately shared over the different converter phases. This configuration would result in a better efficiency and less number of components when compared with a modular DAB configuration. In addition, the output power can be further enhanced by connecting multiple cells of an IBC in a modular output parallel configuration.

\section{CONCLUSION}

For a fast DC charger, considerable several requirements must be taken into accounts such as high power, isolation, low current and voltage ripples etc. In this paper, the two most suitable high-power converter, DAB, and IBC are introduced, analysed, simulated and compared in terms of multiple criteria by using state-of are switching devices e.g. SiC modules. In addition, the strengths and weaknesses of both fast charging architecture approaches have been analysed and discussed.

Based on the discussion, the IBC, when compared to the $\mathrm{DAB}$, is found to be the optimum candidate combining the requirement of a DC charger, in particular, simplicity, high efficiency, very low current ripple and a low number of components.

\section{ACKNOWLEDGEMENT}

The authors would like to thank SP Energy Networks for their partial financial support of this work through the Network Innovation Allowance Project No. RES/0560/7466/002.

\section{REFERENCES}

[1] M. Yilmaz and P. T. Krein, "Review of Battery Charger Topologies, Charging Power Levels, and Infrastructure for Plug-In Electric and Hybrid Vehicles," IEEE Transactions on Power Electronics, vol. 28, no. 5, pp. 2151-2169, May 2013.

[2] L. Rubino, C. Capasso, and O. Veneri, "Review on plug-in electric vehicle charging architectures integrated with distributed energy sources for sustainable mobility," Applied Energy, vol. 207, pp. 438464, Dec. 2017.

[3] "Chademo Brochures," Chademo Association \& Protocol, Mar2018. [Online]. Available: https://www.chademo.com/aboutus/brochures/

[4] "Combined Charging System (CCS)," ChARIN, 23-Jul-2018. [Online]. Available: https://www.charinev.org/faq/. [Accessed: 03Sep-2018]. 
[5] S. Rivera, B. Wu, J. Wang, H. Athab, and S. Kouro, "Electric vehicle charging station using a neutral point clamped converter with bipolar DC bus and voltage balancing circuit," in IECON 2013 - 39th Annual Conference of the IEEE Industrial Electronics Society, 2013, pp. 6219-6226.

[6] S. Bai and S. Lukic, "Design considerations for DC charging station for plug-in vehicles," in 2011 IEEE Vehicle Power and Propulsion Conference, 2011, pp. 1-6.

[7] "SAE Electric Vehicle and Plug-in Hybrid Electric Vehicle Conductive Charge Coupler." SAE Standard J1772, Jan-2010.

[8] O. Veneri, Ed., Technologies and Applications for Smart Charging of Electric and Plug-in Hybrid Vehicles. Cham: Springer International Publishing, 2017.

[9] R. H. Ashique, Z. Salam, M. J. Bin Abdul Aziz, and A. R. Bhatti, "Integrated photovoltaic-grid dc fast charging system for electric vehicle: A review of the architecture and control," Renewable and Sustainable Energy Reviews, vol. 69, pp. 1243-1257, Mar. 2017.

[10] S. Habib, M. M. Khan, F. Abbas, and H. Tang, "Assessment of electric vehicles concerning impacts, charging infrastructure with unidirectional and bidirectional chargers, and power flow comparisons," International Journal of Energy Research, Jan. 2018.

[11] D. Aggeler et al., "Ultra-fast DC-charge infrastructures for EVmobility and future smart grids," in 2010 IEEE PES Innovative Smart Grid Technologies Conference Europe (ISGT Europe), 2010, pp. 1-8. [12] J. W. Kolar, J. Biela, S. Waffler, T. Friedli, and U. Badstuebner, "Performance trends and limitations of power electronic systems," in 2010 6th International Conference on Integrated Power Electronics Systems, 2010, pp. 1-20.

[13] G. E. Sfakianakis, J. Everts, and E. A. Lomonova, "Overview of the requirements and implementations of bidirectional isolated ACDC converters for automotive battery charging applications," in 2015 Tenth International Conference on Ecological Vehicles and Renewable Energies (EVER), 2015, pp. 1-12.

[14] J. W. Kolar, F. Krismer, Y. Lobsiger, J. Muhlethaler, T. Nussbaumer, and J. Minibock, "Extreme efficiency power electronics," in 2012 7th International Conference on Integrated Power Electronics Systems (CIPS), 2012, pp. 1-22.

[15] J. Everts, "Modeling and Optimization of Bidirectional Dual Active Bridge AC-DC Converter Topologies (Modellering en optimalisatie van bidirectionele dual active bridge AC-DC convertor topologieën)," PhD Thesis, KU LEUVEN, ARENBERG DOCTORAL SCHOOL, Leuven, Belgium, 2014.

[16] J. Rabkowski, D. Peftitsis, and H. Nee, "Silicon Carbide Power Transistors: A New Era in Power Electronics Is Initiated," IEEE Industrial Electronics Magazine, vol. 6, no. 2, pp. 17-26, Jun. 2012.

[17] J. Millán, P. Godignon, X. Perpiñà, A. Pérez-Tomás, and J. Rebollo, "A Survey of Wide Bandgap Power Semiconductor Devices," IEEE Transactions on Power Electronics, vol. 29, no. 5, pp. 2155-2163, May 2014.

[18] S. Wang, R. Crosier, and Y. Chu, "Investigating the power architectures and circuit topologies for megawatt superfast electric vehicle charging stations with enhanced grid support functionality," in 2012 IEEE International Electric Vehicle Conference, 2012, pp. 1-8. [19] M. Vasiladiotis and A. Rufer, "A Modular Multiport Power Electronic Transformer With Integrated Split Battery Energy Storage for Versatile Ultrafast EV Charging Stations," IEEE Transactions on Industrial Electronics, vol. 62, no. 5, pp. 3213-3222, May 2015.

[20] S. Rivera and B. Wu, "Electric Vehicle Charging Station With an Energy Storage Stage for Split-DC Bus Voltage Balancing," IEEE Transactions on Power Electronics, vol. 32, no. 3, pp. 2376-2386, Mar. 2017.

[21] S. Habib, M. M. Khan, F. Abbas, L. Sang, M. U. Shahid, and H. Tang, "A Comprehensive Study of Implemented International Standards, Technical Challenges, Impacts and Prospects for Electric Vehicles," IEEE Access, vol. 6, pp. 13866-13890, 2018.
[22] M. Kaltenbach and G. Fenz, "e-Mobility challenges of the operation of high power charging stations," Siemens, Österreich, Austria, Jun. 2017.

[23] K. Uddin, A. D. Moore, A. Barai, and J. Marco, "The effects of high frequency current ripple on electric vehicle battery performance," Applied Energy, vol. 178, pp. 142-154, Sep. 2016.

[24] W. Khan, A. Ahmad, F. Ahmad, and M. Saad Alam, "A Comprehensive Review of Fast Charging Infrastructure for Electric Vehicles," Smart Science, pp. 1-15, Mar. 2018.

[25] "Power Products | Wolfspeed." [Online]. Available: https://www.wolfspeed.com/power/products.

[26] M. N. Kheraluwala, R. W. Gascoigne, D. M. Divan, and E. D. Baumann, "Performance characterization of a high-power dual active bridge DC-to-DC converter," IEEE Transactions on Industry Applications, vol. 28, no. 6, pp. 1294-1301, Nov. 1992.

[27] B. Zhao, Q. Song, W. Liu, and Y. Sun, "Overview of DualActive-Bridge Isolated Bidirectional DC-DC Converter for HighFrequency-Link Power-Conversion System," IEEE Transactions on Power Electronics, vol. 29, no. 8, pp. 4091-4106, Aug. 2014.

[28] J. Everts, "Design and optimization of an efficient (96.1\%) and compact $(2 \mathrm{~kW} / \mathrm{dm} 3)$ bidirectional isolated single-phase dual active bridge AC-DC converter," Energies, vol. 9, no. 10, p. 799, 2016.

[29] Z. Jia and L. Chen, "Design of a bidirectional power interface for V2G technology with smaller DC-link capacitance," International Journal of Smart Grid and Clean Energy, vol. 3, no. 1, Aug. 2013.

[30] R. T. Naayagi, A. J. Forsyth, and R. Shuttleworth, "High-Power Bidirectional DC-DC Converter for Aerospace Applications," IEEE Transactions on Power Electronics, vol. 27, no. 11, pp. 4366-4379, Nov. 2012.

[31] K. George, "Solid-State Transformers for Interfacing Solar Panels to the Power Grid: An Optimum Design Methodology of a High Frequency Transformer for $\mathrm{dc}-\mathrm{dc}$ Converter Applications," The University of Arkansas Undergraduate Research Journal, vol. 20, no. 5, p. 9, 2016.

[32] C. McLyman, Transformer and Inductor Design Handbook, Fourth Edition. CRC Press, 2011.

[33] O. Garcia, P. Zumel, A. de Castro, and A. Cobos, "Automotive DC-DC bidirectional converter made with many interleaved buck stages," IEEE Transactions on Power Electronics, vol. 21, no. 3, pp. 578-586, May 2006.

[34] D. Baba, "Benefits of a multiphase buck converter," Texas Instruments Incorporated, p. 8, 2012.

[35] M. Bendali, C. Larouci, T. Azib, C. Marchand, and G. Coquery, "Design methodology of an interleaved buck converter for onboard automotive application, multi-objective optimisation under multiphysic constraints," IET Electrical Systems in Transportation, vol. 5, no. 2, pp. 53-60, May 2015.

[36] J. C. G. Justino, T. M. Parreiras, and B. J. C. Filho, "Hundreds kW Charging Stations for e-Buses Operating Under Regular Ultra-Fast Charging," IEEE Transactions on Industry Applications, vol. 52, no. 2, pp. 1766-1774, Mar. 2016.

[37] C. Parisi, "Multiphase Buck Design from Start to Finish, Part 1," Texas Instruments, Application Report SLVA882, Apr. 2017.

[38] A. Sewergin, A. H. Wienhausen, K. Oberdieck, and R. W. De Doncker, "Modular bidirectional full-SiC DC-DC converter for automotive applications," 2017, pp. 277-281.

[39] B. Drury, Control Techniques, Drives and Controls Handbook, 2nd Edition. IET Digital Library, 2009.

[40] S. Haghbin, "Design considerations of a $50 \mathrm{~kW}$ compact fast charger stations using nanocrystalline magnetic materials and $\mathrm{SiC}$ modules," in 2016 Eleventh International Conference on Ecological Vehicles and Renewable Energies (EVER), 2016, pp. 1-6.

[41] N. Tan, T. Abe, and H. Akagi, "Design and Performance of a Bidirectional Isolated DC-DC Converter for a Battery Energy Storage System," IEEE Transactions on Power Electronics, vol. 27, no. 3, pp. 1237-1248, Mar. 2012. 